Rabaska

Revue d'ethnologie de l'Amérique française

\title{
Jean-Claude Dupont (1934-2016)
}

\section{Jean-Pierre Pichette}

Volume 14, 2016

URI : https://id.erudit.org/iderudit/1037460ar

DOI : https://doi.org/10.7202/1037460ar

Aller au sommaire du numéro

Éditeur(s)

Société québécoise d'ethnologie

ISSN

1703-7433 (imprimé)

1916-7350 (numérique)

Découvrir la revue

Citer ce document

Pichette, J.-P. (2016). Jean-Claude Dupont (1934-2016). Rabaska, 14, 197-201.

https://doi.org/10.7202/1037460ar

Ce document est protégé par la loi sur le droit d'auteur. L'utilisation des services d'Érudit (y compris la reproduction) est assujettie à sa politique d'utilisation que vous pouvez consulter en ligne.

https://apropos.erudit.org/fr/usagers/politique-dutilisation/
Cet article est diffusé et préservé par Érudit.

Érudit est un consortium interuniversitaire sans but lucratif composé de l'Université de Montréal, l'Université Laval et l'Université du Québec à Montréal. Il a pour mission la promotion et la valorisation de la recherche. https://www.erudit.org/fr/ 


\section{Jean-Claude Dupont (1934-2016)}

Né à Saint-Antonin, comté de Rivièredu-Loup, au Québec, le 27 avril 1934, Jean-Claude Dupont s'est éteint à Québec le 17 mai 2016, à l'âge de 82 ans.

Habitué dès ses études classiques à passer de collège en collège - SaintVictor-de-Beauce, Rivière-du-Loup, Sainte-Anne-de-la-Pocatière, dont la rigueur cadrait mal avec son tempérament d'entrepreneur, puis Bathurst, chez des eudistes plus ouverts - c'est à Pointe-de-l'Église, en NouvelleÉcosse, que Jean-Claude décrocha finalement son baccalauréat ès arts en 1960. Il entreprend alors des études d'ethnologie à l'Université Laval,

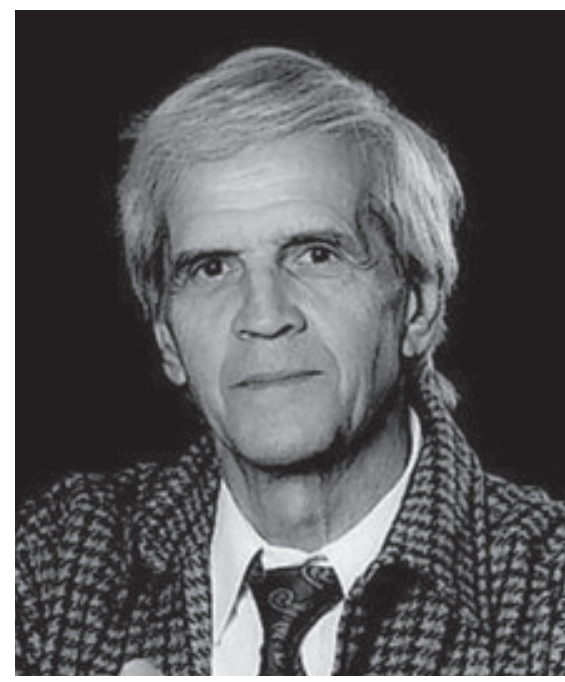

Photo : Marc-André Grenier Source : www.prixduquebec.gouv.qc.ca Québec, où il reçoit une licence ès lettres (1963) puis un diplôme d'études supérieures en présentant un essai sur « Le Forgeron et ses traditions » (1966, XXI-275 p.). Après un séjour d'un an au Centre d'ethnologie française de Paris, situé au Musée des arts et traditions populaires, pour lequel il se mérite un certificat d'études (1974), il couronne ses études à l'Université Laval par un doctorat de troisième cycle, préparé sous la direction de Luc Lacourcière ; sa thèse intitulée « Les Traditions de l'artisan du fer dans la civilisation traditionnelle au Québec » (1974, 2 vol., 691 p.) sera publiée sous le titre L'Artisan forgeron (Québec, les Presses de 1'Université Laval/Éditeur officiel du Québec, 1979, XXXIII-355p.).

À la suite d'un emploi comme auxiliaire de recherche au Département de géographie et au Centre d'études nordiques, Université Laval (19631964), il entame sa carrière de professeur dans des universités des provinces de l'Atlantique, d'abord à Memorial University, à Saint-Jean de TerreNeuve (1964-1965), puis à l'Université de Moncton, Nouveau-Brunswick 
(1965-1967). Revenu à Québec, il travaille provisoirement, à titre de directeur technique, à l'implantation d'un Institut national de la civilisation (1967-1968), ancêtre des Musées de la civilisation. Peu après, il entre définitivement à l'Université Laval (1968) où il gravira tous les échelons - professeur auxiliaire (1968, section ethnographie traditionnelle), professeur adjoint (1971, programme d'arts et traditions populaires), professeur agrégé (1974) et professeur titulaire (1979, programme d'ethnologie du Québec et de l'Amérique française) - jusqu'à sa retraite en 1999. C'est dans ce cadre qu'il inaugurera les études en culture matérielle et en culture acadienne, et formera, par son enseignement et la direction d'une soixantaine de mémoires de maîtrise et de thèses de doctorat, toute une génération de spécialistes qui œuvrent dans cette voie et rayonnent aujourd'hui dans les milieux de la culture et du patrimoine, en muséologie et en recherche notamment. Pendant six ans (1976-1982), il dirigera le Centre d'études sur la langue, les arts et traditions populaires des francophones en Amérique du Nord (CÉLAT) de l’Université Laval.

Au cours de sa vie universitaire, Jean-Claude Dupont aura prononcé plusieurs dizaines de communications et conférences à des colloques, congrès et séminaires (1963-1999), collaboré à de fréquentes émissions de radio et de télévision, et été plusieurs fois professeur invité dans des universités nordaméricaines : à l'Université de Moncton (1973), à l'Institut français du Collège de l'Assomption, Worcester, Massachusetts $(1984,1985)$, à la State University of New-York à Albany (1988) et à l'Université de Sudbury (1991, 1992). Ses enquêtes ethnographiques, menées au Québec, au Nouveau-Brunswick, en Nouvelle-Écosse, à l'Île-du-Prince-Édouard et à Terre-Neuve, ont alimenté les publications qui composent sa volumineuse bibliographe : 71 livres publiés, comprenant une trentaine d'ouvrages personnels, une quinzaine de titres écrits en collaboration, plus d'une vingtaine préparés sous sa direction, sans oublier les deux collections qu'il a dirigées ( «Ethnologie de l'Amérique française », Sainte-Foy, Presses de l’Université Laval,1981-1990 ; « Ethnologie québécoise », Montréal, Hurtubise HMH, 1985-1991), et la série d'ouvrages publiés par les soins des Éditions J.-C. Dupont; et plus de 70 articles parus dans des ouvrages collectifs, des dictionnaires, des revues savantes, des magazines et bulletins d'association, ainsi que des comptes rendus. Ses activités auront été remarquées par des associations professionnelles et des organismes publics qui l'invitèrent à occuper des postes de direction : président de la Société québécoise d'ethnographie et de folklore (1976-1978), président de l'Association canadienne d'ethnologie et de folklore (1984-1986) ; et des postes de conseiller : membre du comité consultatif du Musée du Québec (1984-1986) et membre du comité de développement des collections du Musée de la civilisation de Québec (1988-1991). 
À partir de 1984, il s'adonnera, parallèlement à ses travaux universitaires, à l'illustration des légendes et des coutumes de l'Amérique française, produisant une iconographie considérable de plus de trois cents toiles; elles ont fait l'objet de nombreuses expositions, lancées souvent dans la région de Québec et qui ont par la suite circulé dans des musées un peu partout au Québec (Bonaventure, Kamouraska, Joliette, Mont-Joli, Montréal, Péribonka, TroisRivières), au Canada (Sudbury, Vancouver, Pointe-de-l'Église), aux ÉtatsUnis (Boston, Manchester, Orono, Miami) et jusqu'en Europe (Parthenay, Châtellerault, La Rochelle en France; Moscou en Russie) et en Asie (Japon). Il en a tiré une douzaine de livrets populaires que diffuse la maison d'édition qu'il a lui-même fondée. En 1996, le Château Mont-Tremblant, un hôtel du Pacifique canadien de la région de Montréal, l'invitait à réaliser des œuvres peintes pour une exposition permanente dont on fit tirer des sérigraphies.

Ses travaux universitaires lui ont mérité des distinctions nombreuses et convoitées. Ces prix et honneurs insignes, qui jalonnent son parcours, ont graduellement salué le travail du pionnier : son élection à la Société royale du Canada (Académie des sciences humaines, 1981), sa désignation comme membre honoraire de la tribu des Abénakis (Odanak, Québec, 1985), son agrégation à l'Ordre des francophones d'Amérique (1992), l'adjudication de la médaille Marius-Barbeau (Association canadienne d'ethnologie et de folklore ; 1993), l'hommage décerné par Icomos, partenaire de l'Unesco, en reconnaissance de la mise en valeur du patrimoine (1996), et, comme points culminants, l'attribution de l'un des Grands Prix du Québec, le prix GérardMorisset pour le patrimoine (1998), ainsi que des doctorats honorifiques de l'Université de Moncton (2004) et de l'Université Sainte-Anne (2012), en constituent certes les plus prestigieuses.

$$
* * *
$$

J'ai connu Jean-Claude Dupont durant presque cinq décennies à des titres divers. Comme étudiant d'abord, je fus de la première classe à qui il a enseigné à son arrivée à Laval en 1968, et qu'il a, comme tant d'autres, incité à présenter des communications dans des colloques en le pressant surtout de terminer sa thèse sans délai ; comme jeune collaborateur aussi qu'il a conscrit pour la création de la collection « Mémoires d'homme » dans la foulée du succès d'édition de ses Contes de bûcherons; il n'hésita pas encore à m'encourager à professer en périphérie, en Ontario et en Nouvelle-Écosse, ses séjours dans les provinces atlantiques l'ayant persuadé qu'en dehors de l'Université Laval, il y avait aussi un salut pour l'ethnologie ; comme jeune collègue enfin qu'il a soutenu de ses conseils dans de nombreux projets et intégré dans son réseau de chercheurs de l'Amérique française. Je suis d'ailleurs persuadé que c'est à la confiance et à l'amitié qu'il m'a accordées, au fil de toutes ces années, 
que je dois le privilège d'avoir reçu ses confidences au moment de sa retraite en 1999 ; cette longue entrevue devait nourrir les mélanges Entre Beauce et Acadie, qu'avec Jocelyne Mathieu, Richard Dubé, Yves Bergeron et une quarantaine de collègues et amis nous lui avons offerts en 2001.

Car Jean-Claude Dupont s'inscrit dans la vénérable lignée des grands ethnologues d'ici : innovateur comme ses prédécesseurs, les Marius Barbeau et les Luc Lacourcière, c'est lui qui a lancé l'enseignement de la culture matérielle au Québec. Chez Jean-Claude, l'ethnologie, un terme qu'il a très tôt contribué à propager, ne s'arrêtait pas sèchement aux divisions classiques de la discipline. Sa thèse en culture matérielle, L'Artisan forgeron, exprime bien la nécessité qu'il éprouvait « d'étudier [un] métier tant dans ses aspects techniques que dans ses traditions », ce qu'il appelait le « folklore du métier », notamment les coutumes et la littérature orale qu'il véhiculait, plaçant dès lors au cœur de son étude l'informateur-artisan qui témoigne de sa pratique. Ainsi, bien avant la notion de patrimoine culturel immatériel qui a cours aujourd'hui, son flair d'enquêteur, qui lui avait déjà servi à nuancer et à faire tomber quelques préjugés, lui avait en outre enseigné que la culture populaire forme un tout indivisible, comme l'être humain, et que le chercheur ne devait jamais l'oublier.

De tous les professeurs de son département, il aura été, je crois bien, le tout premier docteur en ethnologie et l'un des diffuseurs les plus inventifs de notre patrimoine : à côté de dizaines de livres scientifiques, il a produit autant d'ouvrages de vulgarisation - il était fier de l'autoédition d'une douzaine de petits recueils de légendes qui dépassait le demi-million d'exemplaires diffusés - et aussi des centaines de toiles illustrant les légendes de l'Amérique française ; « de la peinture naïve » disait-il, qu'il faisait par plaisir, dont on a pourtant tiré de grandes expositions qui ont voyagé jusqu'en Russie et au Japon. La détermination, l'esprit d'initiative et l'assiduité au travail expliquent la réussite du nomade discret de Saint-Antonin qui validait quotidiennement que « c'est en forgeant qu'on devient forgeron », proverbe qu'il a su appliquer à toutes les facettes de son œuvre.

Il n'oublia jamais cette Acadie qui lui ouvrit alors la voie de sa prodigieuse carrière. Un demi-siècle plus tard, le samedi 12 mai 2012, en l'église SainteMarie du même endroit, j'ai eu le bonheur de présenter mon ami Jean-Claude Dupont au grade de Docteur honoris causa de l'Université Sainte-Anne. En lui conférant ce titre, affecté pour la première fois de la mention « études acadiennes ", son alma mater saluait chez cet ancien diplômé l'ethnologue étoile qui avait rangé l'Acadie au centre de ses recherches. Après la série de distinctions convoitées qui ont jalonné son parcours, je crois que l'honneur que lui décerna cette minuscule institution acadienne, celle qui l'avait rescapé 
en des temps plus difficiles, le toucha vraiment. C'était notre façon de lui dire combien son cheminement était exemplaire et que son œuvre demeurerait comme un phare pour les générations montantes.

L' « ineffable » Jean-Claude, comme le qualifiait gentiment son maître, Luc Lacourcière, a rejoint au panthéon des anciens l'infatigable Marius et le grand Luc, qui ont, comme lui, maîtrisé l'art de l'enquête orale pour pénétrer avec simplicité et naturel l'âme des gens ordinaires de ce pays. Face aux obstacles dressés sur leur route, tous, ils ont su relever la tête et afficher une belle ingéniosité, animés qu'ils étaient par le feu sacré plus que par les petites glorioles personnelles. J'ose croire que leur exemple nous inspirera pour dissiper les heures sombres que traverse présentement l'ethnologie au Québec.

JeAn-Pierre Pichette Société québécoise d'ethnologie 